J.Lake Sci.(湖泊科学), 2016, 28(1): 1-8

DOI 10. 18307/2016. 0101

(c) 2016 by Journal of Lake Sciences

\title{
生态文明的自然本原”
}

\author{
谢 平 \\ (中国科学院水生生物研究所东湖湖泊生态系统试验站, 武汉 430072)
}

摘 要: 何为生态文明的自然本原? 它就是良性的生态循环. 生态文明的自然基础是一系列生态系统的良性循环一一森 林生态系统、草地生态系统、农业生态系统、湖泊生态系统、河流生态系统、海洋生态系统……等等, 而良性循环的标志有 二:1) 为人类提供清洁的水源、新鲜的空气、优质的农一牧一渔产品、舒心的休闲景观等,这些是我们身心健康的前提,没 有它们的支撑, 人类文明的大厦将难以为继;2) 为珍惜濒危以及土著物种提供良好的栖息之地,维持良好的生态平衡关 系,增加生态系统对外界干扰的可塑性.

关键词: 生态文明;生态系统;良性循环

\section{Natural arche of ecological civilization}

\section{XIE Ping}

(Donghu Experimental Station of Lake Ecosystems, Institute of Hydrobiology, Chinese Academy of Sciences, Wuhan 430072, P.R.China)

Abstract: What is the natural arche of ecological civilization? It is balanced cycling of a series of ecosystems, such as forest ecosystem, grassland ecosystem, agriculture ecosystem, lake and river ecosystems and marine ecosystems, etc. The standard of balance means fresh and clean water and air, high quality products of agriculture, animal husbandry and fisheries, pleased leisure landscape, natural habitats for native and endangered species, and maintenance of ecological balance and strong resilience to external disturbances.

Keywords: Ecological civilization; ecosystem; balanced cycling

文明(Civilization)一词源自拉丁文“Civis”, 意指城市的居民,原意为人民生活于城市和社会集团中的能 力. 在人类学中, 人类文明常指有人居住并形成一定经济文化的地区, 通俗地说, 文明意味着从野蛮中的挣 脱. “文明”一词如同“生态”一词一样被泛化,譬如,工业文明、农业文明、社会文明、精神文明、基督教文明、 儒家文明、中华文明、印度文明、两河文明、黄河文明......数不甚数. 当两个泛化的词加在一起造出“生态文 明”一词时,如何才能精确解读呢? 它已是一种重要的政治理念,被解读为 “人一自然一社会的和谐发展”. 问题是,人类社会可以发展, 但自然只有缓慢的演化,因此,这多少有些瑕疪. 解读“生态文明” 的自然本原亦 是生态学家义不容辞的职责……

天地万物之道, 唯有循环. 我们人类寄居的这个自然界是由无数种大大小小的循环构成的一种极为错 综复杂的地球系统. 譬如,季节的更替是人人都容易理解的一种对称性循环: 春一夏一秋一冬,周而复始,循 环往复, 它起因于地球绕太阳的周期运动. 生物圈中的生产者一消费者一分解者则是一种在生态系统水平 的物质循环, 它贯穿了一系列特定生源要素 ( $\mathrm{C} 、 \mathrm{~N} 、 \mathrm{P} 、 \mathrm{~S}$ 等) 的循环. 植物的发芽一生长一开花一结果是在生 物个体水平的一种生活史循环. 而细胞中的三羧酸循环、卡尔文循环等则是生化水平的代谢循环……因此, 大自然就是循环! ${ }^{[1]}$.

\section{1 生命一一相互嵌套的一系列循环}

循环就是规律、秩序和稳定性, 没有它, 生命将不复存在. 或者说, 生命的本质就在于循环.

*2015-11-23 收稿. 谢平 (1961 ), 男, 博士, 研究员; E-mail: xieping@ihb.ac.cn. 


\section{1 生化水平的循环一一艾根的超循环}

诺贝尔化学奖得主一一德国化学家艾根 (Manfred Eigen) 在《超循环论》一书中将生化水平的循环分为 3 个层次一一应循环、催化循环和超循环 (hypercycle).

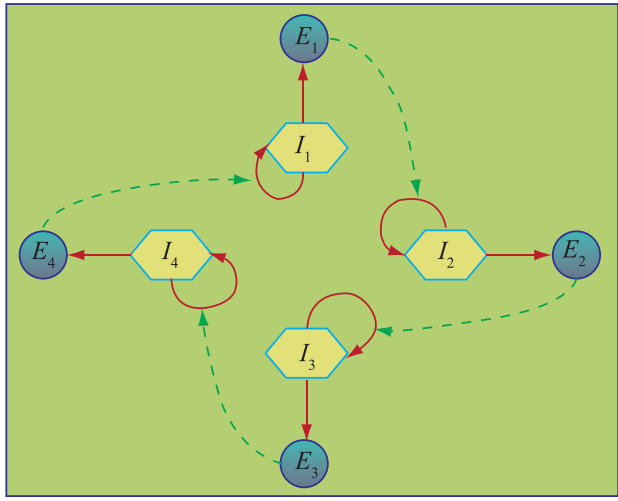

图 1 一个假想的超循环的示意图 (每个红色的 环表示单个的自催化系统, 绿色的虚线表示

一个自催化组分对另一个的放大效应)

(引自 Luiz Alexandre Silva)

Fig.1 An imaginary schematic of hypercycle (Each red cycle indicates single self-autocatalytic system, Green dashed line indicates amplified effect of one self-autocatalytic component to another) ( cited from Luiz Alexandre Silva)

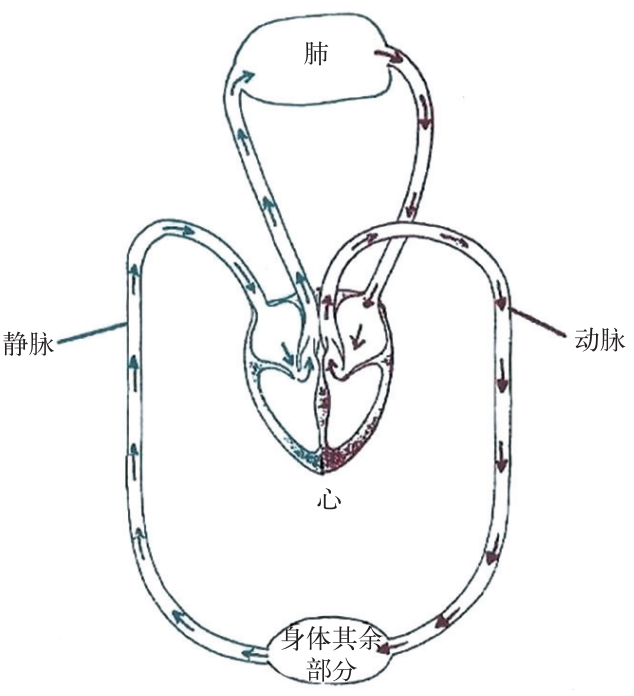

图 2 血液循环的示意图 (引自 www.tattoodonkey.com)

Fig. 2 Schematic of blood cycling ( cited from www.tattoodonkey.com)
(1) 反应循环:酶所催化的反应就是这一类, 在这类 反应循环中, 反应物通过催化剂的作用, 生成产物, 最后 催化剂又返回到起始状态; 这样, 在一定的期限内, 酶可 以循环使用.

(2) 催化循环: 这一类反应循环中, 至少有一步是自 催化反应, 即至少有一个中间产物是自催化剂 (所谓自催 化是指反应的产物本身又作为催化剂, 加速或延缓反应 物向产物变化), 例如, DNA 的自我复制, 就是一种催化 循环.

(3) 超循环: 这是一类由循环构成的循环, 或者说, 由 反应循环耦合起来的催化循环就称为超循环; 这里主要 是指功能上循环耦合联系起来的循环, 即所谓的催化超 循环; 在超循环组织中, 每一个组元既能自复制, 又能催 化下一个组元的自复制. 超循环本身还可以再分为不同 的等级,如基本的超循环、复合超循环等.

图 1 就是一个假想的催化超循环系统, 含有两种大 分子的, 多核苷酸 $\left(I_{i}\right)$ 被多肽 $\left(E_{i}\right)$ 所催化, 后者又是前者 的转录产物. 艾根的超循环理论认为, 反应循环是一个自 我再生的过程, 催化剂经过一个循环又再生出来; 催化循 环是一个自我复制的过程, 产物自身作为催化剂又指导 反应物再生出产物; 超循环不仅自我再生、自我复制, 而 且还能自我选择、自我优化, 从而向更高级的复杂性 进化 ${ }^{[1-2]}$.

\section{2 组织水平的循环一一血液循环}

英国人哈维( William Harvey) 是著名的生理学家和 医生, 也是近代生理学的奠基人之一. 他通过对数十种 动物的实验研究, 发现了血液循环的规律, 即血液受心 脏推动, 沿着动脉血管流向全身各部, 再沿着静脉血管 流回心脏,这是一个(在有生之年) 永不停息的循环过程 (图 2). 他于 1628 年出版了《心血液运动论》, 公布了他 的理论.

\section{3 个体的生活史循环}

霍尔巴赫(1723-1789 年) 指出: “同一个动物, 因为 它的机体的性质,会连续不断地从简单的需要走向复杂 的需要, 而这些需要, 同样也是它的本性的结果. 譬如, 我们所赞美的美丽的蝴蝶就是这样, 最初, 它是一个没 有生命的卵, 热力从这卵中孵出一条虫来, 虫变成蛹, 接 着它就变成一只我们看到的有着最鲜明的色彩的带翅 的昆虫: 达到这种形态之后, 它便传种繁殖; 最后完成自 然交给它的任务,或者走完自然为它的族类划就的变化 的圈子之后, 它就是被剥去装饰, 而必须消逝” (图 3$)^{[4]}$. 
霍尔巴赫说, 类似的变化存在于一切植物中, 人的情形也是 如此. 诗人歌德在“人性的界限”一诗(创作于 1781 年) 中形 象地说道, “一个小小的圆圈圈住了我们一生,世世代代的 人持久地排在我们的生存之无尽的链条上”.

\section{4 生态系统/生物圈中的元素循环}

在生态系统/生物圈中各种生源要素奔流不息, 循环往 复——碳循环、氮循环、磷循环, 等等. 以碳循环为例, 大致 可分为碳的生物循环和非生物循环两种基本过程. 碳的生 物循环包括光合作用和呼吸作用两个基本过程:

光合作用: 大气中的 $\mathrm{CO}_{2}$ 进人陆生和水生态系统 (图 4), 绿色植物 (包括低等藻类) 运用光合色素吸收和传输太 阳能 $(\mathrm{E})$, 并通过光化学反应裂解水, 放出氧的同时, 将 $\mathrm{CO}_{2}$ 还原成简单的糖类, 用于体内的一系列生物合成与代谢. 光 合作用的总反应式如下:

$$
6 \mathrm{CO}_{2}+6 \mathrm{H}_{2} \mathrm{O}+\mathrm{E} \longrightarrow \mathrm{C}_{6} \mathrm{H}_{12} \mathrm{O}_{6}+6 \mathrm{O}_{2}
$$

呼吸作用: 光合作用所产生的一部分有机化合物在植物

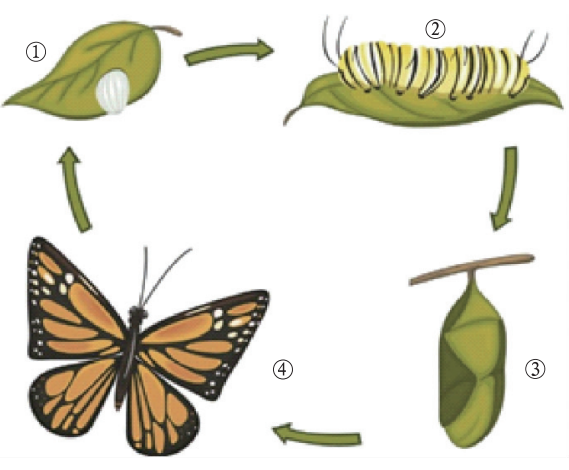

图 3 蝴蝶的生活史

( (1)卵一(2)幼虫一(3)蛹一(4)成虫的循环)

(来源: www.edplace.com)

Fig.3 Schematic of the life history of butterfly ( cycle of (1) egg-(2) larva-(3) pupa-(4) adult) ( cited from www.edplace.com) 体内、或通过异养微生物、或通过牧食/腐食食物链在动物体 内被分解产生生物能量、 $\mathrm{CO}_{2}$ 和水:

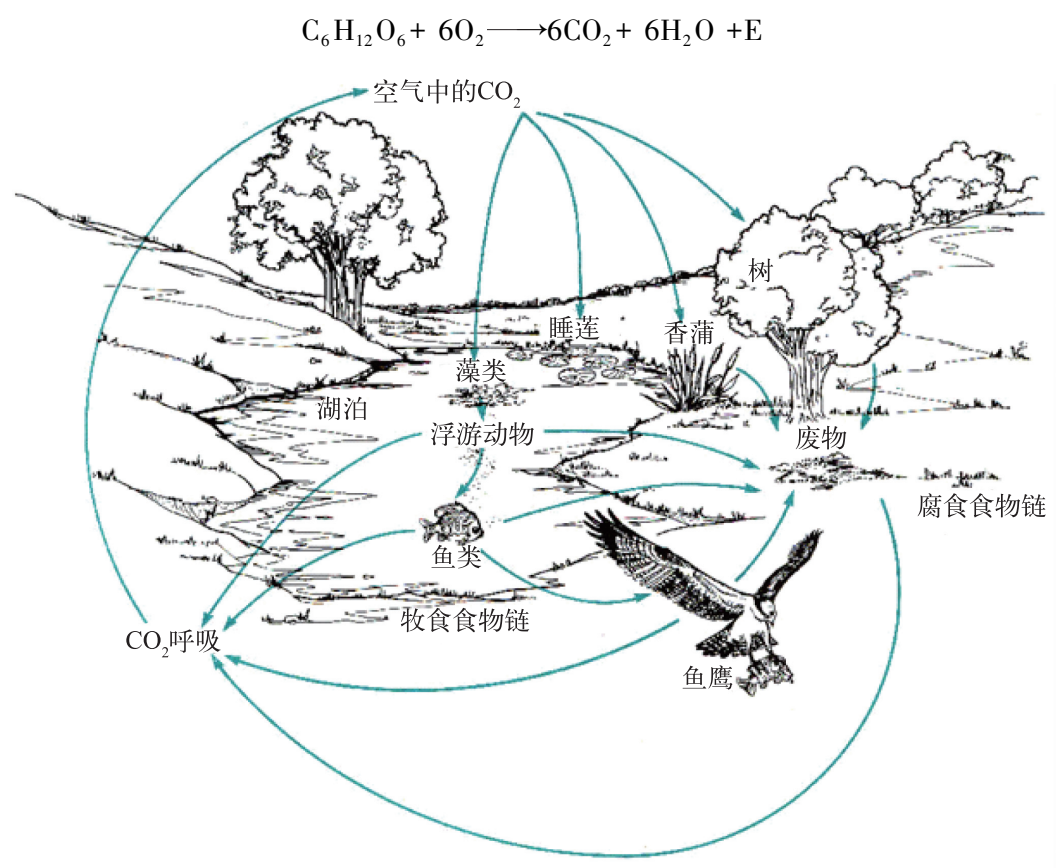

图 4 碳的生物化学循环示意图 (碳在环境(空气和水)与生物体之间往复循环. 碳被植物和藻类捕获, 流向牧食者、肉食者和分解者. 在这些生物体内, 为获取能量有机物被分解并释放出 $\mathrm{CO}_{2}$, 使碳的循环得以持续 ${ }^{[5]}$ )

Fig.4 Schematic of the biochemical carbon cycle( Carbon cycles back and forth between the environment ( air and water) and organisms. It is trapped by plants and algae and passed to hervivores, carnivores, and decomposers. Carbon dioxide is released by the breakdown of organic materials for energy in these organisms, thus continuing the cycle ${ }^{[5]}$ ) 
这是光合作用的逆反应. 毫不夸张地说, 在地球的生命圈层中, 没有什么比这两个方程式反应的过程更 为重要的了!

此外, 碳还有一种非生物的循环过程. 由地球内热驱动的构造过程不断地将海洋的沉积层冲人地幔中, 其后又作为火成岩被火山过程流回. 在这个过程中, $\mathrm{CO}_{2}$ 被火山释放到大气中,再被风化作用所消耗(图 5).

可以设想, 如果没有有机质的分解与消耗, 地球表面早就被植物残骸厚厚地覆盖, 生命自身或许早就不 复存在了. 但是这并未发生, 而且分解者和消费者还能利用植物的“废物”- $-\mathrm{O}_{2}$, 又将植物固定的基本物质 $\left(\mathrm{CO}_{2}\right)$ 归还给大气, 这真是自然界的神奇啊! 这种关系演绎得如此淋漓致尽一使得包括我们人类在内的所 有动物离开了植物的废弃物- $\mathrm{O}_{2}$ 便无法生存了! 可以推测, 在动物诞生之前, 原始海洋的生命系统可能 只被结构简单的生产者和分解者所统治, 随着动物的诞生和植物的登陆, 生命才迎来了前所未有的扩张与 繁荣.

需要指出的是, 大自然虽然如此聪明, 但也决非那样的尽善尽美. 其实, 看似平衡的循环实则并非如此. 如果是平衡的, 那为何地球诞生以来, 大气圈的氧气会不断上升? 为何有那么多的石油和煤炭在地下得以 埋葬 (虽然人类正一步步地将它们燃烧殆尽送返回大气圈) ? 很显然, 这是一种通过短期的循环来推动长期 缓慢变化的模式. 当然, 在自然界的历史长河之中, 人类, 作为动物界的一员 (许多现代的人类似乎正在逐步 淡忘这样的记忆), 正在以前所未有的强悍, 不断地改造着自然的进程, 特别是不解地强化自然界的整体呼 吸作用而削弱整体光合作用, 以满足人们的财富与享乐, 但谁知未来的福兮祸兮!

总之,生命的存在与运行就是通过在各种不同生命层次 (生化、组织、个体和生态系统) 上的一系列循环 来实现的, 如在生态系统中元素的地化循环、个体的生活史循环、组织的物质循环和细胞中的生化反应循环 (如三羧酸循环等). 因此, 它们就是生命车轮中的车轮, “碾”出了尘世中的姹紫嫣红、万花掩映! 连一些重 要的生物分子 (如苯环、吡咯环、嘌呤环、嘧啶环、吡嗪环等) 也是环状的, 没有这些象征着循环意义的有机化 合物, 所有的生命根本不会存在. 令人百思不得其解的是, 为何生命要在各种花样中变幻着这种循环或环形 的游戏呢? 莫非是为了去追逐一种永恒的象征? 或者干脆承认, 生命的本质就是循环, 虽然它不是永恒, 但 它借用了这种永恒的法则, 通过一个又一个卑微而短暂的循环向那宏伟的种族永恒不断延绵! 就像一个永 恒的圆圈是由无数的点所构成一样, 个体恰似这渺小的点, 而种族亦如那飞舞旋转的圈！

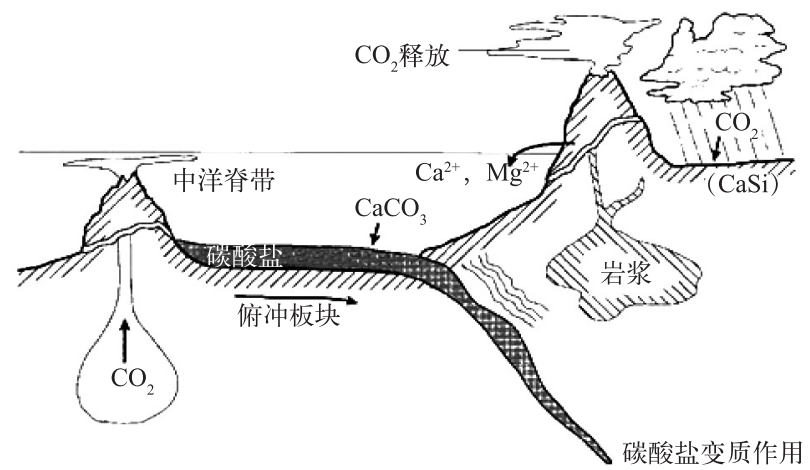

图 5 碳的地球化学循环示意图 $\left(\mathrm{CO}_{2}\right.$ 从与中洋脊带的岩浆室相通的火山口中逃逸到海洋和大气中. $\mathrm{CO}_{2}$ 与土壤和岩石中的硅酸盐进行交换, 置换出 $\mathrm{Mg}^{2+}$ 和 $\mathrm{Ca}^{2+}$, 而 $\mathrm{Mg}$ 和 $\mathrm{Ca}$ 则通过河流进入海洋. 在海洋, $\mathrm{Mg}$ 和 $\mathrm{Ca}$ 又以碳酸盐的形式沉淀,沉降到板块边界的上层地幔中. 俯冲带的 $\mathrm{CO}_{2}$ 在高温高压的条件下被释放, 聚集在与火山相通的岩浆室中 ${ }^{[5]}$ )

Fig. 5 Schematic of the geochemical carbon cycle $\left(\mathrm{CO}_{2}\right.$ is outgassed to the ocean and atmosphere from magma chambers feeding volcanoes at mid-ocean ridges. The $\mathrm{CO}_{2}$ exchanges with silicates in soils and rocks, and mobilizes $\mathrm{Mg}$ and $\mathrm{Ca}$ ions, that are carried to the oceans by rivers. In the oceans, the $\mathrm{Mg}$ and Ca precipitate as carbonates and are subducted into the upper mantle at plate boundaries. $\mathrm{CO}_{2}$ is released from the subducting carbonates at high temperatures and pressures, and accumulates in magma chambers, where it feeds volcanoes ${ }^{[5]}$ ) 


\section{2 地貌与宇宙的循环往复}

除了生命的循环往复之外, 地球与宇宙亦可能如此. 与短暂的人生相比, 宇宙与地貌的显著变化是无与 伦比的漫长自然过程, 因此, 宇宙循环只是一种假说, 地貌循环则是一种根据知识进行的间接推理, 虽然是 极为可能的.

\section{1 地貌一一隆升与侵蚀的轮回}

早在古希腊,亚里士多德就在《天象学》中指出, “地球的相同地区并非总是潮湿或干燥, 而是依据河 流的生成与干枯发生变化. 因此, 陆地与海洋也发生 变化, 并非一些始终是陆地, 另一些始终是海, 而是在 曾为陆地的地方现在成了海, 现在是海的地方又重新 变成陆地. 我们必须认为, 这种变化依照某种次序, 而 且是循环的……当河流在一个地方退落并消失时, 就 相应地在另外的地方生成……既然时间是无限的, 宇 宙是永恒的, 那么, 塔奈斯河与尼罗河就都不会永远流 淌, 它们曾经流经的地方总有一天要干涸; 因为它们的 行为有界限, 而时间却没有. 同样的说法也适于一切 其他河流” ${ }^{[6]}$. 当然, 这与赫拉克利特万物皆变的观念 并无本质差别.

1899 年, 美国地理学家戴维斯提出了“地貌轮回 说” 或 “侵蚀轮回说” 的学说 ${ }^{[7]}$ : 构造运动使地壳隆升 成山地, 之后不断经受流水的侵蚀, 可区分为以河流下 蚀作用为主的幼年期, 以侧蚀作用为主的壮年期和侵 蚀微弱地面降低为缓坡的老年期, 到最后地面被夷平 为准平原. 然后地壳再次隆升, 进人下一个轮回. 这即 所谓河流侵蚀轮回 (图 6). 类似地还有风蚀轮回、冰蚀 轮回和海蚀轮回等. 因此, 地貌是构造、营力和时间的 产物. 当然, 地貌的循环变化并非是一种绝对对称性
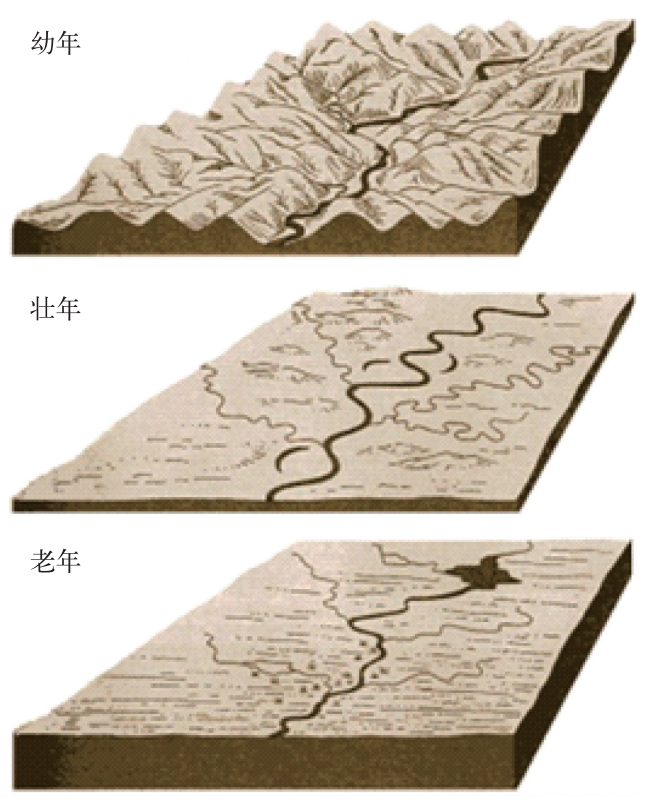

图 6 河流侵蚀轮回中不同时期的示意图 (引自 www.staff.amu.edu.pl)

Fig.6 Schematic of the cycle of river erosion at different stages ( cited from www.staff.amu.edu.pl) 的循环过程.

\section{2 宇宙一一无始无终, 循环往复}

天体物理学家提出了所谓的循环宇宙模型理论, 认为宇宙无始无终, 即宇宙既没有 “诞生”之日, 也没有 终结之时, 只是在一次又一次大爆炸一大反冲之中循环往复, 以至无穷. 最近 Frampton 等提出了一种称为 “小撕裂模型” 来支持循环宇宙模型理论, 它是基于这样的一种推理, 即所能观测到的“可见物质”仅占宇宙 质量的很小一部分, 而占据主导地位的是暗能量, 这种神秘物质的密度似乎是不随时间改变的, 这就意味 着, 即便宇宙随时间推移不断膨胀, 暗能量将不会随之被稀释. 而且, 随着宇宙的无限膨胀, 物质连接物、原 子和分子等基本粒子、甚至亚原子粒子都将被撕裂. 既然所有的物质都被撕裂了,那么它们还能再次聚合在 一起, 形成新的恒星和星系, 循环往复, 这样就解决了传统的循环宇宙模型中面临的熵的悖论问题. 其实, 只 有回到循环之上,宇宙之生灭的合理性才会更容易扎根于人类的心灵或认知之中.

\section{3 哲学意境中的循环}

2000 多年前, 古希腊哲学家就开始从事物的生成与消灭来探讨自然界中事物的循环. 那时人们还缺乏 关于物质构成的科学认识, 哲学家只是提出了许多关于物质成分的假说. 在他们看来, 只要是物质性的存 在, 它的生成就不可能无中生有, 而它的消灭也不是化为乌有. 


\section{1 古希腊时代}

对古希腊的哲学家来说, 无论他们认为世界的本原是一种单一的成分或是多种成分, 他们都认为物质 循环地生成与消灭, 譬如, 泰勒斯 (约公元前 624一前 546 年) 提出万物是从水产生的,最后又复归为水; 赫拉 克利特 (约公元前 540 年一前 480 年) 说, “火生于土之死, 气生于火之死, 水生于气之死, 土生于水之死”. 伊 壁鸠鲁 (Epicurus, 约公元前 342 或 341 -前 270 年) 在论人的死亡与痛苦时, 也谈到了一种物质的循环, 他 说, 死亡不会使任何人烦恼, 因为只有活着的人才有痛苦或快乐的感觉, 人死了之后, 就没有感觉了. 这是因 为构成我们身体和心灵的原子散开了, 也就是说不再有这个特殊的身体和心灵了, 有的只是大量的各不相 同的原子而已,这些原子回复到物质的原初存在,继续进行新的构成物的循环之中.

阿那克西曼德 (约公元前 610-546 年)认为同时并存着许多世界和宇宙体系,它们全都会消灭,在它们 的创生和毁灭之间有一种不断的交替, 并相信这个循环的过程是有严格的必然性的: “万物由之所生的东 西, 万物毁灭后由于必然性复归于它; 因为万物按照时间的秩序, 为它们彼此间的不正义而受到惩罚并相互 补偿” ${ }^{[8]}$. 他认为一切事物都有开端, 而“无限”没有开端, 世界自它而生, 又复归于它.

汤姆逊在《古代哲学家》一书中说,在赫拉克利特 (约公元前 540-480 年)看来, ““在这一循环的边缘 上, 开端和终结是相同的'. 每一个终结就是一个开端, 因此, 既没有开端, 又没有终结; 世界是永恒的” ${ }^{[9]}$.

亚里士多德在《论生成与消灭》中对事物的生成与消灭问题进行了系统的论述与分析 ${ }^{[10]}$, 认为宇宙的 生成不衰在于万物的循环生成与消灭. 他说: “如果事物的生存是必然的, 它的生存就是永恒的, 而如果是永 恒的, 也就是必然的. 因此, 如果某物的生存是纯粹必然的, 它就必定是循环的, 即返回自身. 因为生成必然 要么有限度, 要么无限度; 如果无限度, 它必定要么是直线式, 要么是圆圈式. 但是, 如果生成是永恒的, 就不 可能是直线式, 因为它没有开端, 无论我们向下考虑 (当作将发生的事) 还是向上追溯 (当作已出现过的事). 但生成必然有开端, 虽然不是有限的, 而是永恒的. 因此它必然是圆圈式……正是圆圈式的运动和生成中, 才有纯粹的必然, 也就是说, 如果过程是圆圈式, 其中的每一个环节必然会生成或已经生成, 如果过程是必 然的, 它们的生成就是圆圈式” ${ }^{[10]}$. 这精彩地诠释了必然性一永恒性一无限性一循环性之间的辨证关系. 正 如亚里士多德所说“既然无限没有开端, 也就不会有使其他环节必然生成的第一者”, 他相信必然的生成必 定是一种返回自身的循环方式.

\section{2 古罗马时代}

古罗马诗人卢克莱修(约前 99 年一约前 55 年)在《物性论》一书中说, “我将为你揭示事物的始基, 自然 用它来创造一些,用它来繁殖和养育一切,而当一件东西终于被颠覆的时候,她又使它分解为这些始基. 在 我的论说中我想把这些东西叫做质料、产生事物的物体、事物的种子或原初物体, 因为万物以它们为起点而 获得存在……任何东西都不绝对消灭, 虽然看起来好像如此; 因为自然永远以一物建造他物, 从不让任何东 西产生, 除非有他物的死来作补偿” ${ }^{[11]}$. 卢克莱修说, “原初物体有坚实的单一性, 否者它们就不能被保存 着, 经过亿万年, 经过无限的时间, 以备补充消竭了的许多个世界”. 这与留基波、德谟克利特以及伊壁鸠鲁 等的原子学说一脉相承,这些与现代科学所揭示的元素的特性惊人地一致!

\section{3 近代}

法国哲学家霍尔巴赫(Paul-Henri Dietrich baron'd Holbach,1723-1789 年) 在其于 1770 年匿名发表的专 著《自然的体系》中描述道: “动物、植物和矿物, 到了一定时期, 就要把它们从自然借来的那些原素或原质, 归还给自然, 就是说, 重新放在事物的总的堆积里面, 重新放回万有的大仓库里去. 那时候, 土重新收回曾经 作为物体之基础和坚固性的那一部分;空气则取得与它自己类似的部分以及最稀薄最轻的部分; 水带走它 所易于分解的那部分; 火则断绝它和原有事物的联系, 自由地去同其他物体配合. 这样解组、解体、分化、分 散了的动物的基础部分, 将要形成新的配合; 它们用来养活、保持、或是来毁灭新的事物, 而在其他一些植物 中, 等到它们成熟了, 便来养活和保持新的动物; 这些新的动物, 轮到它们, 又来遭受和最初那些动物所遭受 的同样的命运. 这就是自然永恒不变的进程; 这就是一切存在的事物必须循行的永恒的循环. 就是这样, 运 动使宇宙的各部分这一些从那一些地产生出来、保存一些时候、然后又相继地被它们破坏掉, 而存在物的总 和却是永远一样的” ${ }^{[3]}$. 由于那时自然科学的知识十分有限, 霍尔巴赫对一些现象描述在现在看来也已经不 是十分准确了, 但是他领悟到了自然 (按现在的科学语言就是生态系统) 中物质的永恒循环, 甚至似乎已经 
朦胧地影射出了生产一消费一分解这一生态系统的核心循环过程.

德国哲学家黑格尔 (1770-1831 年) 精辟地阐述了认识的无限循环过程, 他在《逻辑学》一书中在解释 哲学开端时指出: “开端的规定性, 是一般直接的和抽象的东西, 它的这种片面性, 由于前进而失去了; 开端 将成为有中介的东西, 于是科学向前运动的路线, 便因此而成为了一个圆圈……那个造成开端的东西, 因为 它在那里还是未发展的、无内容的东西, 在开端中将不会被真正认识到, 只有在完全发展了的科学中, 才有 对它的完成了的、有内容的认识, 并且那才是真正有了根据的认识” ${ }^{[12]}$. 也就是说, 他并不认为开端就是绝 对真理, 而需要一个不断循环发展的过程而接近绝对真理. 在这里, 黑格尔似乎是借用了赫拉克利特关于 “在圆周上, 起点和终点是同一的” 的说法, 并将其引申到了认识过程. 黑格尔 (还有赫拉克利特) 的这种辩 证思维被一些现代科学家所仿效. 黑格尔在他的《自然哲学》一书中指出: “个体性把自身规定为特殊性或有 限性, 而又否定这种有限性, 并向自身回归, 在过程的终点使自己恢复为开端, 这是一个无限的过程” ${ }^{[13]}$.

让我们欣赏哲学家叔本华对自然界之循环所作的精辟阐述吧, 他说, “不论在哪里都无例外, 自然的纯 粹象征是圆形, 因为圆形是循环的图示. 这实是自然界中最普遍的形式, 上至天体的运行, 下至有机体的生 生死死, 万物之中的所行所为, 只有借这种图示, 才可能在时间的流动中产生一种现实存在, 即眼前的自 然”. 诗人歌德曾说, “让开端跟着结束紧紧地结合一处”, 这循环的寓意恰如该诗 (创作于约 1801 年) 的题 名—“变化中的持续”!

\section{4 良性循环一一生态文明的本原}

古希腊哲学家认为,一切皆流, 无物常住, 这似乎是在说世事瞬息万变. 但是没有万物的相对稳定性, 何 以有万物之存在呢? 世间的万事万物都不可能永恒存在, 就像生命, 有生的那一刻, 就必定会有死的那一刹. 哲学家用了两个词——生成”与“消灭”来形容这样的过程. 而唯有循环一词既可意味永恒的变化,也可意 味永恒的存在. 生态文明是一种和谐共生、良性循环和持续繁荣的统一体, 其中核心的是要维持好地球生命 系统在一定平衡域附近震荡的良性循环, 这才是生态文明的本原, 因为它为人与自然的和谐共生与持续繁 荣提供基础.

当然, 和谐共存也是相对的, 因为人类为了自身的生存已经消灭了无数的物种, 而且还在继续使数不胜 数的物种濒临灭绝. 因此,我们只能在现在的情境下去使自身的行为更为文雅或友善一些. 而何谓“持续繁 荣” 呢? 如果繁荣等同于增长, 那这是不可能的, 因为, 增长速率总有一天会趋于零, 这亦是可持续的必然前 提. 因此,持续繁荣必须是持续的良性循环,否则地球总有一天会走向崩溃.

生态文明的自然基础是一系列生态系统的良性循环一一森林生态系统、草地生态系统、农业生态系统、 湖泊生态系统、河流生态系统、海洋生态系统……等等, 而良性循环的标志有二: 1) 为人类提供清洁的水源、 新鲜的空气、优质的农一牧一渔产品、舒心的休闲景观等, 这些是我们身心健康的前提, 没有它们的支撑, 人 类文明的大厦将难以为继;2) 为珍惜濒危以及土著物种提供良好的栖息之地, 维持良好的生态平衡关系, 增 加生态系统对外界干扰的可塑性.

能够长期生活于良性生态循环中的人类社会就是一个生态文明的社会. 为此, 需要政治家、科学家、企 业家和社会大众等的精诚合作, 联手去探索各式各样的维持良性循环的生态模式. 在这里,生态学的专业知 识至关重要, 特别是由中央和部委的研究机构 (如中国科学院、中国环境科学研究院、中国水利科学研究院、 中国农业科学研究院等)、高等院校等在各类生态系统中积累的长期监测与研究资料, 这是科学决策的基 础. 因此, 国家科技管理部门应整合与建设一个全覆盖、可共享的系统的生态环境监控体系并维持其长期稳 定的运行, 为生态文明社会的设计、建设与运行提供生态科技上的支撑. 在此基础上, 重整现行的农牧渔业、 工业及其它产业模式, 建设规模化的生态农业、生态渔业(图 7)、生态草业以及海绵城市 (图 8) 等新模式, 并 在实践中不断优化. 当然,还需要去培育生态文明的伦理一一善待自然,呵护自然,这亦是善待和呵护自身!

请不要忘记, 人本来就是自然界的一部分, 是一种必须依赖于植物生产的有机物为生的 “寄生者” (至少 从目前来看, 这种属性不大可能会被科技的进步所改变, 因为人造光合作用的成功还遥遥无期, 而实用就更 是天方夜谭了), 因此, 对自然关系 (循环) 的过度改变或破坏总有一天会殊及自身. 从生态学的视角来看, 人 类的文明史其实是一部 “蹂躏”与 “毁灭” 自然的历史, 现在我们要将这两个对立面撮合成一个统一体, 试图 


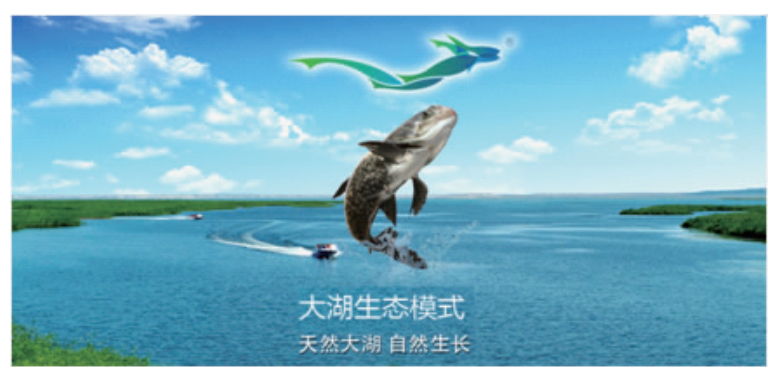

图 7 新型大湖生态模式一一多样的物种, 美丽的景色, 清洁的水质, 优质的渔产品

Fig.7 New eco-fisheries model of great lakes with maintenance of diverse species, beautiful scenery, clean water and high-quality fisheries products

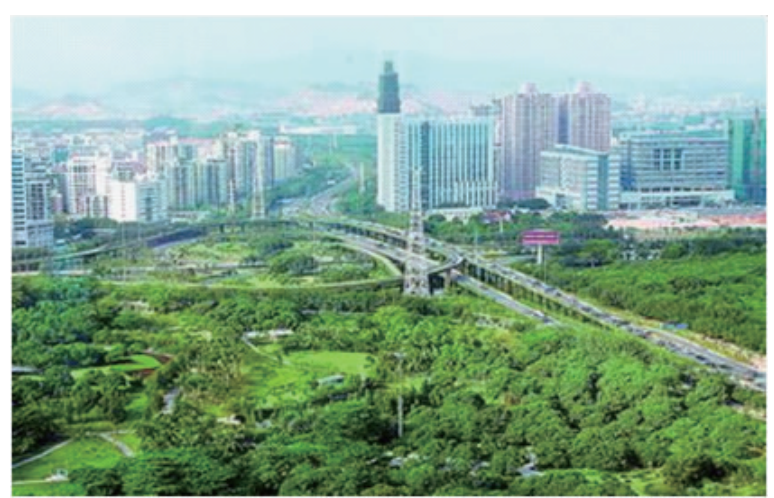

图 8 美丽的海绵城市一一兼具蓄水与净水功能 (来源: 中国城市-中国城市资讯网)

Fig.8 A beautiful sponge city with both storage and purification of water ( source: City. China.Com.CN)

用生态的车轮来搭载人类的文明, 有望实现传统文明的真正超越……!

\section{5 参考文献}

[ 1 ] 谢 平. 生命的起源一一进化理论之扬弃与革新. 北京: 科学出版社, 2014.

[2] 沈晓峰,曾国屏. 超循环论的哲学问题. 中国社会科学, 1989: 185-194.

[3] 霍尔巴赫. 管士滨译. 自然的体系 (上卷). 北京: 商务印书馆, 1964.

[ 4 ] Chiras DD. Environmental science, action for a sustainable future. California: The Benjamin/Cummings Publishing Company Inc, 1991.

[ 5 ] Falkowski PG. Chapter 12 on the evolution of the carbon cycle. In: Williams PJ le B, Thomas DN, Reynolds CS eds. Phytoplankton productivity, carbon assimilation in marine and freshwater ecosystems. Blackwell Science, 2002.

[6] 亚里士多德. 徐开来译. 天象学. 见: 苗力田编. 亚里士多德全集 (第二卷). 北京: 中国人民大学出版社, 1991: 469-602.

[ 7 ] Davis WM. The geographical cycle. Geographical Journal, 1899, 14: 481-504.

[ 8 ] 斯通普夫 SE, 菲泽 J. 匡宏等译. 西方哲学史一一从苏格拉底到萨特及其后(修订第 8 版). 北京: 世界图书出版公 司, 2008 .

[ 9 ] 屈万山.《赫拉克利特著作残篇》评注. 西安: 陕西师范大学出版社, 1987.

[10］亚里士多德. 徐开来译. 论生成与消灭. 见: 苗力田编. 亚里士多德全集 (第二卷). 北京: 中国人民大学出版社, 1991:393-468.

[11] 卢克莱修. 方书春译. 物性论. 北京: 商务印书馆, 1981.

[12］黑格尔. 杨一之译. 逻辑学(上卷). 北京: 商务印书馆, 1982.

[13] 黑格尔 GWF. 梁志学等译. 自然哲学. 北京: 商务印书馆, 1986. 